\title{
Influence of fluorine on thermal properties of lead oxyfluoride glass
}

\author{
Manuela Reben • Marcin Środa
}

Received: 8 October 2012/ Accepted: 5 February 2013/Published online: 28 February 2013

(c) The Author(s) 2013. This article is published with open access at Springerlink.com

\begin{abstract}
Oxyfluoride glasses are the basic materials for obtaining transparent glass-ceramic (TGC) which can be used in a wide range of optoelectronics devices such as: amplifiers, up-conversion, telescopes, laser sources. Oxyfluoride TGC is obtained by the control heat treatment of the parent glass due to low phonon nanocrystalline phases. The oxyfluoride glasses from the sodium-lead-silica system were the object of investigation. The influence of fluoride content on the thermal properties of glasses was analyzed. Thermal characteristics of glasses like the transition temperature $T_{\mathrm{g}}$, the temperature for the crystallization onset $T_{\mathrm{x}}$, and the maximum crystallization temperature $T_{\mathrm{c}}$, thermal stability parameter were determined by DTA/DSC method. The linear expansion coefficients of oxyfluoride glasses as a function of temperature were measured using a thermomechanical analyzer (TMA 7 Perkin-Elmer). The effect of crystallization on the thermal expansion coefficient and softening temperature $T_{\mathrm{s}}$ was found.
\end{abstract}

Keywords Oxyfluoride glass $\cdot \mathrm{PbF}_{2} \cdot$ Transparent glass-ceramics $\cdot$ Thermal expansion coefficients . Crystallization

\section{Introduction}

Transparent oxyfluoride nano-glass-ceramics (GC), made photo-luminescent by doping with rare-earth ions, have

M. Reben · M. Środa $(\varangle)$

Faculty of Materials Science and Ceramics, AGH_University

of Science and Technology, al. Mickiewicza 30,

30-059 Cracow, Poland

e-mail: msroda@agh.edu.pl

M. Reben

e-mail: manuelar@agh.edu.pl been shown recently to be promising materials for new optical devices such as bulk laser media and amplifying laser fibers for optical communications [1-4]. These materials are easier to prepare than single crystals and can be made in a wide variety of shapes and sizes; they are also characterized by high chemical and mechanical stabilities as oxides [1-4]. Oxyfluoride GC can be obtained by the process of the heat treatment of glass close to the glass transition temperature, in which fluoride crystallites are dispersed in the oxide glass matrix [5-8]. GCs are also used for joining glass-to-metal, and ceramic to metal and also as a bonding media (like a thin glue layer) between bulk materials. These functions find numerous applications in various disciplines of science and technology. The main requirement for the formation of a high quality seal or coating is to achieve ideal bonding structure at the interfaces $[9,10]$. Further, the thermal expansion coefficients of both the metal and ceramic should match as closely as possible to minimize the stresses. Generally, the GCs exhibit a wide range of thermal expansion coefficients depending upon the composition and the presence of relative proportions of the crystalline phases [11]. The thermal expansion coefficients of GC can be remarkably different from those of the parent glass and are basically controlled by the crystallization process. In this paper, the influence of fluoride content on the thermal properties of glasses was analyzed. Fluorine, which is the most electronegative element of the periodic table, is known to be a powerful network disrupter, which is substituted for bridging oxygens (because the ionic radii of these two elements are similar), in the structure of glasses, forming non-bridging oxygen and fluorine atoms. As a result of this destructive substitution, glass viscosity and the glass transition temperature $\left(T_{\mathrm{g}}\right)$ decrease drastically [12]. Fluorine content has been shown to have a strong effect on the reduction of the glass 
transition temperature in a variety of glass systems such as fluoro-alumino-silicate, calcium-fluoro-aluminate, phosphor-fluoro-alumino-silicate, phosphorfluoro calcium-alumino-silicate, phosphor-fluoro-silicate, and fluoro-silicate glasses [13, 14].

Fluorine also aids crystallization by lowering the viscosity which causes a better mobility of atoms and rearrangement of them to form crystals. Fluorine usually acts as a nucleating agent, and as it promotes melt crystallization, oxyfluoride glasses are less stable compared with oxide glasses. The thermal expansion coefficient of oxyfluoride glasses rise with increasing the amount of fluorine [15]. Considering the information mentioned above, in this paper, we placed the emphasis on the study of relationship between the chemical composition and the linear expansion coefficients of transparent oxyfluoride glass and GC.

\section{Experimental}

\section{Samples preparation}

The batch was based on the $\mathrm{SiO}_{2}-\mathrm{PbO}-\mathrm{PbF}_{2}-\mathrm{Na}_{2} \mathrm{O}$ glass system. The following raw materials were used to prepare the batches: silica oxide $\left(\mathrm{SiO}_{2}\right)$, lead oxide $(\mathrm{PbO})$, lead fluoride $\left(\mathrm{PbF}_{2}\right)$, sodium oxide $\left(\mathrm{Na}_{2} \mathrm{O}\right)$. All the chemicals were mixed properly to ensure the homogeneity. Oxyfluoride glass was obtained by melting $50 \mathrm{~g}$ batches in platinum crucibles in an electric furnace at temperature of $850{ }^{\circ} \mathrm{C}$ in air atmosphere. The crucible was covered with a platinum plate to avoid vaporization losses. The melt was poured out onto a steel plate which was preheated at $330{ }^{\circ} \mathrm{C}$, forming a layer thickness of $2-5 \mathrm{~mm}$, then annealed at a temperature $20{ }^{\circ} \mathrm{C}$ below $T_{\mathrm{g}}$, and subsequently polished with commercial media and water-free lubricant. The samples can be obtained with good transparency and uniform thickness of $0.2 \mathrm{~cm}$ and $2.0 \mathrm{~cm}$ diameter. The composition of the investigated glasses is listed in Table 1. The XRD system analysis was used to confirm the amorphous nature of glass.

\section{Method used}

The ability of the obtained glasses to crystallize was determined by DTA/DSC measurements conducted on the NETZSCH 5 System operating in heat flux DSC mode. The samples $(60 \mathrm{mg})$ were heated in platinum crucibles at a rate $10{ }^{\circ} \mathrm{C} \min ^{-1}$ in dry nitrogen atmosphere to the temperature $1100{ }^{\circ} \mathrm{C}$. The glass transition temperature $T_{\mathrm{g}}$ was determined from the inflection point on the enthalpy curve; the jump-like changes of the specific heat $\Delta C_{\mathrm{p}}$ accompanying the glass transition, enthalpy $\left(\Delta H_{\mathrm{cer}}\right)$ of cerammization of $\mathrm{PbF}_{2}$, and crystallization of the glass matrix were calculated using the NETZSCH 5 Thermal Analysis Software
Library. The ability of glasses for crystallization was measured by the values of the temperature $\left(T_{\text {cryst. }}\right)$, the enthalpy of crystallization $\left(\Delta H_{\text {cryst. }}\right)$, and the values of the thermal stability parameter of glasses $\left(\Delta T=T_{\text {cryst. }}-T_{\mathrm{g}}\right)$. Glasses revealing the effect of cerammization were selected for further thermal treatment. To obtain GC with nanocrystallization of $\mathrm{PbF}_{2}$, they were subjected to heating for $30 \mathrm{~min}$ at the temperature of the maximum ceramming effect, respectively. The kind and the size of the formed crystallites were examined by XRD method with the use of Philips X'Pert X-ray Diffractometer with $\mathrm{CuK} \alpha$ radiation source. The thermal expansion measurements were conducted on the Perkin-Elmer TMA-7 Analyzer with the heating rate of $5^{\circ} \mathrm{C} \mathrm{min}^{-1}$.

\section{Results and discussion}

Glasses from the $\mathrm{SiO}_{2}-\mathrm{PbO}-\mathrm{PbF}_{2}-\mathrm{Na}_{2} \mathrm{O}$ system during heating demonstrated, besides the thermal effect characteristic for typical phase transitions occurring in a glassy material, an additional exothermal effect near the $T_{\mathrm{g}}$ temperature connected with $\mathrm{PbF}_{2}$ crystallization. This effect is observed only for three definite chemical compositions of the examined glasses (Fig. 1). Analysis of DTA curves

Table 1 Chemical composition of oxyfluoride glass

\begin{tabular}{lllcl}
\hline ID & \multicolumn{4}{l}{ Glass composition/mol\% } \\
\cline { 2 - 5 } & $\mathrm{SiO}_{2}$ & $\mathrm{PbO}$ & $\mathrm{PbF}_{2}$ & $\mathrm{Na}_{2} \mathrm{O}$ \\
\hline 0 & 55 & 35 & 0 & 10 \\
1 & 55 & 30 & 5 & 10 \\
2 & 55 & 25 & 10 & 10 \\
3 & 55 & 20 & 15 & 10 \\
\hline
\end{tabular}

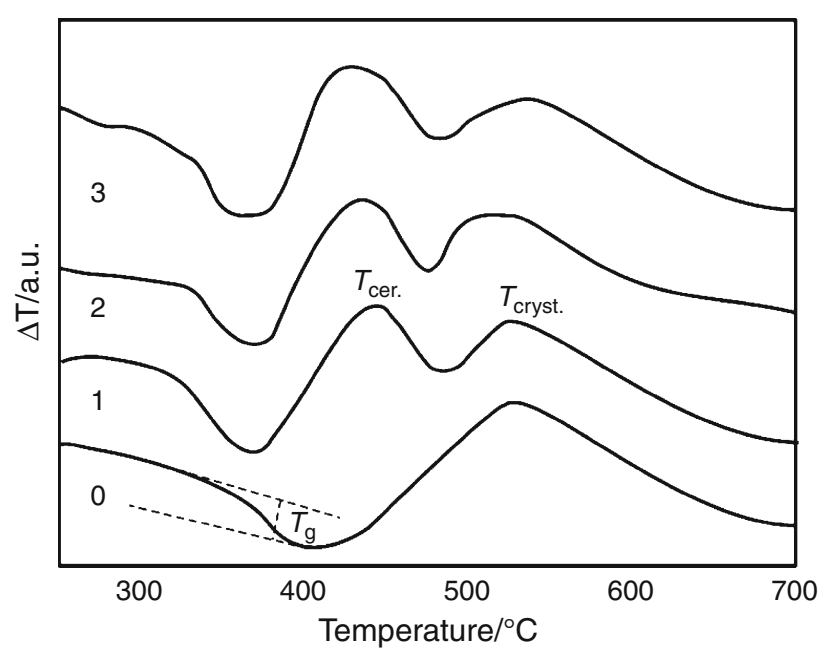

Fig. 1 DTA curves of oxyfluoride glasses 
Table 2 Thermal characteristics of oxyfluoride glass

\begin{tabular}{|c|c|c|c|c|c|c|c|c|}
\hline & \multicolumn{3}{|l|}{ TMA } & \multicolumn{4}{|c|}{ DTA/DSC } & \multirow{2}{*}{$\begin{array}{l}\text { Crystallizing } \\
\text { phases }\end{array}$} \\
\hline & $\alpha_{25-325} \times 10^{-6} /{ }^{\circ} \mathrm{C}$ & $T_{\mathrm{g}} /{ }^{\circ} \mathrm{C}$ & $T_{\mathrm{s}} /{ }^{\circ} \mathrm{C}$ & $T_{\mathrm{g}} /{ }^{\circ} \mathrm{C}$ & $\Delta C_{\mathrm{p}} / \mathrm{J} \mathrm{g}^{-1}{ }^{\circ} \mathrm{C}^{-1}$ & $T_{\text {max.cer. }} /{ }^{\circ} \mathrm{C}$ & $\Delta T=T_{\text {max.cer }}-T_{\mathrm{g}} /{ }^{\circ} \mathrm{C}$ & \\
\hline \multicolumn{9}{|c|}{ Glass no. } \\
\hline 0 & 10.38 & 377 & 406 & 399 & 0.215 & 530 & & $\mathrm{PbO}$ \\
\hline 1 & 10.45 & 363 & 392 & 361 & 0.201 & 458 & 97 & $\mathrm{PbF}_{2}$ \\
\hline 2 & 10.60 & 360 & 391 & 354 & 0.137 & 446 & 92 & $\mathrm{PbF}_{2}$ \\
\hline 3 & 11.39 & 357 & 390 & 349 & 0.114 & 439 & 90 & $\mathrm{PbF}_{2}$ \\
\hline \multicolumn{9}{|l|}{ GC no. } \\
\hline $1 \mathrm{GC}$ & 10.37 & 367 & 412 & & & & & \\
\hline $2 \mathrm{GC}$ & 10.56 & 369 & 416 & & & & & \\
\hline $3 \mathrm{GC}$ & 10.30 & 379 & 422 & & & & & \\
\hline
\end{tabular}

$T_{\mathrm{g}}$, transition temperature; $T_{\mathrm{s}}$, softening temperature; $\mathrm{T}_{\text {max.cer. }}$, temperature of maximum cerammization

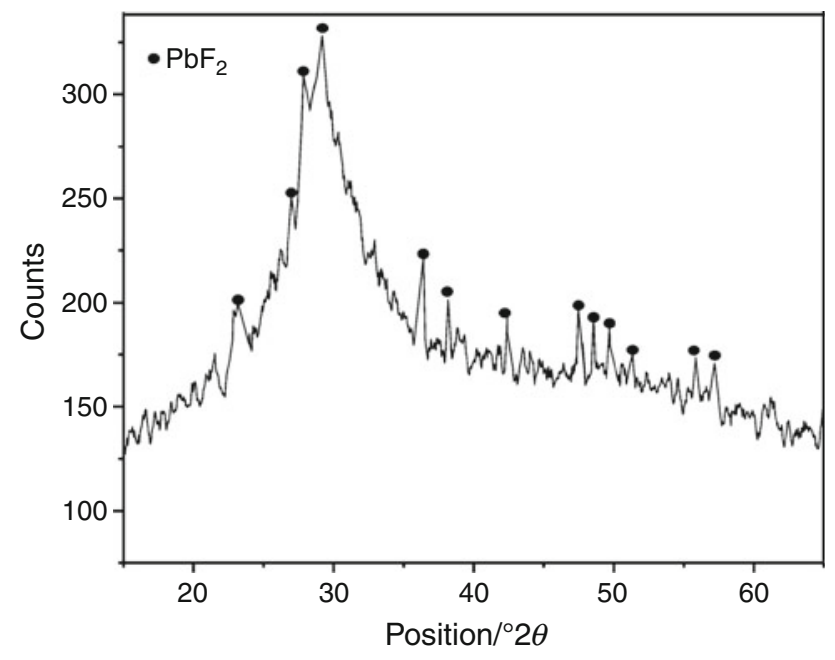

Fig. 2 XRD pattern of glass 1 after the thermal treatment at $458{ }^{\circ} \mathrm{C}$ for $30 \mathrm{~min}$

indicates that the presence of a well visible effect of the glassy state transformation in the examined glasses is closely connected with the cerammization effect (Fig. 1). In all studied glasses, the second crystallization event at the temperature $500-600{ }^{\circ} \mathrm{C}$ is observed. This effect is also connected with $\mathrm{PbF}_{2}$ formation but with micrometer size of crystals. Increase of fluorine content introduced into the structure of glasses by $\mathrm{PbF}_{2}$ causes a decrease of the glass transition temperature $T_{\mathrm{g}}$ and a decrease of changes of the specific heat $\Delta C_{\mathrm{p}}$ accompanying the glass transition region (Table 2). This has been explained on the basis of the strength of the chemical bond between the components of the considered glass structure, according to Görlich [16]. Introduction of increasing amounts of $\mathrm{Pb}-\mathrm{F}\left(i_{\mathrm{G}}=0.715\right)$ and $\mathrm{Si}-\mathrm{F}\left(i_{\mathrm{G}}=0.506\right)$ bonds characterized by the considerable ionicity into the glass structure at simultaneous reduction of $\mathrm{Pb}-\mathrm{O}\left(i_{\mathrm{G}}=0.670\right), \mathrm{Si}-\mathrm{O}\left(i_{\mathrm{G}}=0.428\right)$ of a lower ionicity increases the flexibility of the glass structure.

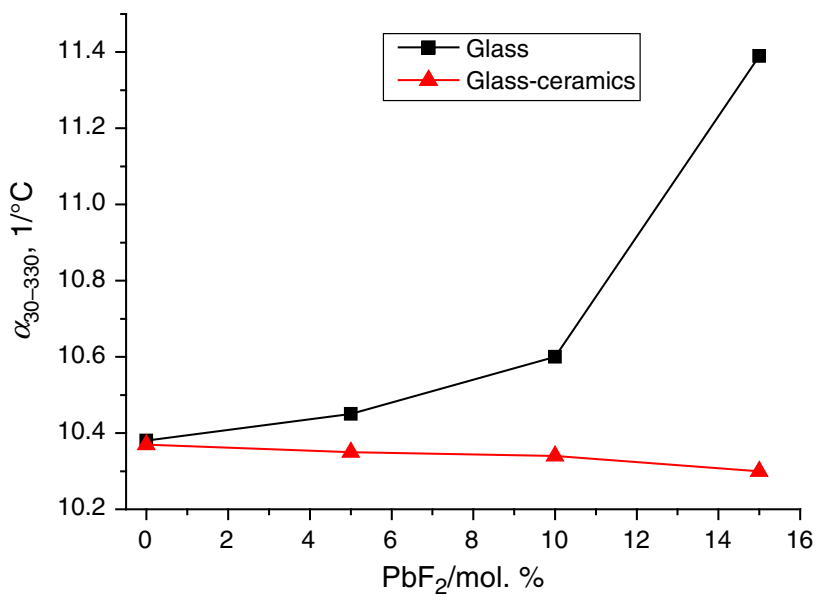

Fig. 3 Effect of $\mathrm{PbF}_{2}$ content on the thermal expansion coefficient of glass and GC

As a consequence, the number of structural strains, the relaxation of which requires a small amount of energy, is decreasing. Thus the glass transition region occurs at lower temperature and is accompanied by a small change of the specific heat. The introduction of fluorine ions, replacing the oxygen ions in the glass structure, increases the tendency of glass to undergo $\mathrm{PbF}_{2}$ crystallization. The temperature of the initial effect of cerammization is shifted toward lower temperatures. This is evidence of the increasing ability of the glass for cerammization, manifested by decreased value of the index of thermal stability parameter $\Delta T$ (Table 2). Increase of fluorine content causes a slight decrease of the temperature of the second crystallization event, as well as a gradual disappearance of the effect. The formation of $\beta-\mathrm{PbF}_{2}$ phase is observed at the first stage of crystallization and $\alpha-\mathrm{PbF}_{2}$ at the second stage; thus increasing amount of fluorine in the glass structure causes the break of lead-silicate glass matrix crystallization. This can be explained by the fact that crystallization 


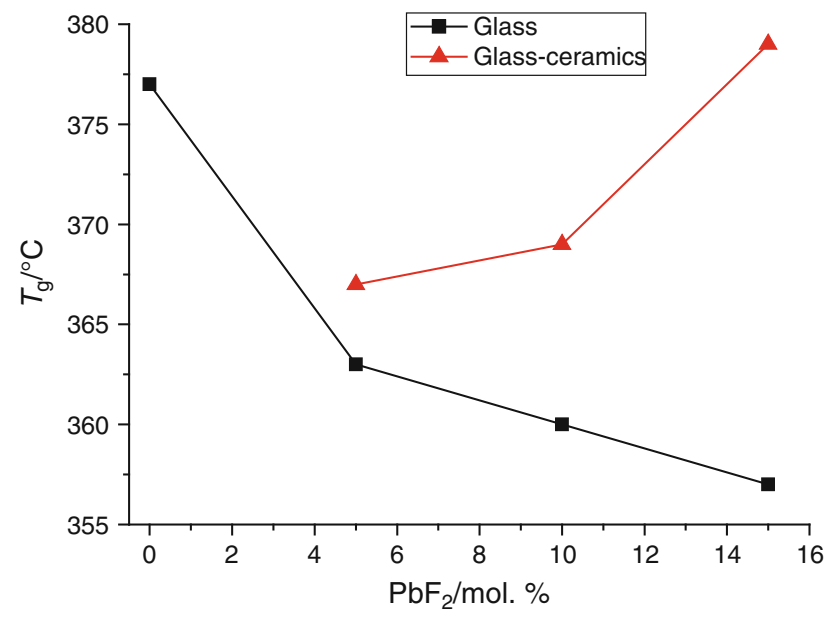

Fig. 4 Effect of $\mathrm{PbF}_{2}$ content on the transition temperature $\left(T_{\mathrm{g}}\right)$ of glass and $\mathrm{GC}$ obtained from dilatometric curves

process usually starts in those components whose bonds can be easily broken.

XRD measurements for the glass no. 1 obtained by the heat treatment at its first crystallization effect temperature showed several diffraction peaks overlapped on the amorphous hump, which indicates that crystals are precipitated from the precursor glasses (Fig. 2). It is easy to identify that the crystal phase is $\beta-\mathrm{PbF}_{2}$. By naked eyes, the GC samples are transparent after the heat treatment.

The thermal expansion is ascribed to the asymmetry of the amplitude of thermal vibrations in the glass. In turn, the asymmetric vibrations can be related to the chemical bonding and composition. An increase of the number of non-bridging bonds would weaken the structure and increase the coefficient of thermal expansion. Thus oxide by fluorine ions replacement leads to an increase in the thermal expansion coefficient in the oxyfluoride glass (Fig. 3).

A reverse effect is observed after the thermal treatment of glass and $\mathrm{PbF}_{2}$ formation. The more fluoride in the glass and $\mathrm{PbF}_{2}$ crystallites in the samples, the lower the thermal expansion coefficient is revealed. Simultaneously, ceramming process induces a change of the transition temperature calculated as a deflection point of the dilatometric curve. The increase of fluorine content diminishes the residual glass transition temperature. GC samples are characterized by the higher value of the glass transition temperature in comparison with the residual glass (Fig. 4). A similar effect is observed for the softening temperature $\left(T_{\mathrm{s}}\right)$ calculated as a maximum point of the dilatometric curve (Fig. 5). The results show that ceramming process changes the thermal durability of materials. After crystallization, the rest of the glass becomes more oxide. The higher value of the transition temperature and softening temperature are caused by the tightened glass network.

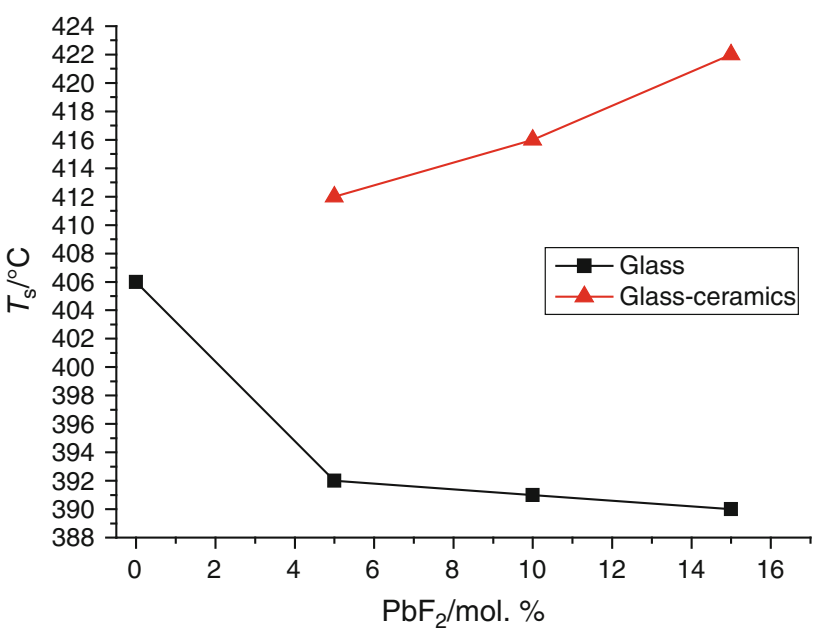

Fig. 5 Effect of $\mathrm{PbF}_{2}$ content on the softening temperature $\left(T_{\mathrm{s}}\right)$ of glass and GC obtained from dilatometric curves

In the case of $\mathrm{GC}$, the lower values of the thermal expansion coefficients are observed in comparison with those of residual glass. The more intensive effect of ceramming and easier $\mathrm{PbF}_{2}$ formation, the lower thermal expansion coefficients are revealed. This phenomenon can be explained by the lower contribution of fluorine of the remaining glassy matrix in the GC.

\section{Conclusions}

The thermal properties of $\mathrm{SiO}_{2}-\mathrm{PbO}-\mathrm{PbF}_{2}-\mathrm{Na}_{2} \mathrm{O}$ glass system were investigated; the conclusions can be drawn as follows:

1. In the $\mathrm{SiO}_{2}-\mathrm{PbO}-\mathrm{PbF}_{2}-\mathrm{Na}_{2} \mathrm{O}$ glass system, the transparent $\mathrm{GC}$ with the $\mathrm{PbF}_{2}$ nanocrystallites can be obtained.

2. The addition of fluorine into the examined glasses increases the coefficient of thermal expansion, and decreases the value of glass transition temperature.

3. The presence of increasing amount of fluorine as a network disrupter caused the reduction of the dilatometric softening temperature of oxyfluoride glass.

4. The introduction of fluorine ions, replacing the oxygen ions in the glass structure, increases the tendency of glass to $\mathrm{PbF}_{2}$ crystallization.

5. The ceramming process leads to a reduction of the thermal expansion coefficient, caused by a higher durability of the remaining continuous glass matrix.

The thermal expansion of glasses below the glass transition range is important for glass-to-metal bonding in the lighting industry; it plays a vital role for optimizing the time-temperature cooling schedule of glass fibers, and it 
enables the development of glass sealing materials as well as the design of specialty glass products that are exposed to varying temperatures.

Acknowledgments This study was supported by the Statutory Activities No. 11.11.160.365 (2013) of Faculty of Materials Science and Ceramics, AGH-University of Science and Technology, al. Mickiewicza 30, 30-059 Cracow, Poland.

Open Access This article is distributed under the terms of the Creative Commons Attribution License which permits any use, distribution, and reproduction in any medium, provided the original author(s) and the source are credited.

\section{References}

1. Wang Y, Ohwaki J. New transparent vitroceramics codoped with $\mathrm{Er}^{+}$and $\mathrm{Yb}^{3+}$ for efficient frequency upconversion. Appl Phys Lett. 1993;63:3268-71.

2. Tick PA, Borreli NF, Cornelius LK, Newhouse MA. Transparent glass ceramics for $1300 \mathrm{~nm}$ amplifier applications. J Appl Phys. 1995;78:6367-74.

3. Dejneka MJ. The luminescence and structure of novel transparent oxyfluoride glass-ceramics. J Non-Cryst Solids. 1998;239:149-55.

4. Mortier M, Goldner P, Chateau C, Genotelle M. Erbium doped glass-ceramics: concentration effect on crystal structure and energy transfer between active ions. J Alloy Compds. 2001;323:245-9.

5. Kawamoto Y, Kanno R, Qiu J. Upconversion luminescence of $\mathrm{Er}^{3+}$ in transparent $\mathrm{SiO}_{2}-\mathrm{PbF}_{2}-\mathrm{ErF}_{3}$ glass ceramics. J Mater Sci. 1998;33:63-7.
6. González-Pérez S, Martín IR, Rivera-López F, Lahoz F. Temperature dependence of $\mathrm{Nd}^{3+} \rightarrow \mathrm{Yb}^{3+}$ energy transfer processes in co-doped oxyfluoride glass ceramics. J Non-Cryst Solids. 2007;353:1951-5.

7. Zhao D, Qiao X, Fan X, Wang M. Local vibration around rare earth ions in $\mathrm{SiO}_{2}-\mathrm{PbF}_{2}$ glass and glass ceramics using $\mathrm{Eu}^{3+}$ probe. Phys B Condens Matter. 2007;395:10-5.

8. Reben M. The thermal study of oxyfluoride glass with strontium fluoride. J Non-Cryst Solids. 2011;357(14):2653-7.

9. Zanchetta A, Lefort P. Thermal expansion and adhesion of ceramic to metal sealings: case of porcelain-Kovar junctions. J Eur Ceram Soc. 1995; 15:233-8.

10. Motoc DL, Ivens J, Dadirlat N. Coefficient of thermal expansion evolution for cryogenic preconditioned hybrid carbon fiber/glass fiber-reinforced polymeric composite materials. J Therm Anal Calorim. doi:10.1007/s10973-012-2560-7.

11. Wang M, Cheng J. Viscosity and thermal expansion of rare earth containing soda-lime-silicate glass. J Alloy Compd. 2010;504: 273-6.

12. Stamboulis A, Hill RG, Law RV. Characterization of the structure of calciumalumino-silicate and calciumfluoro-alumino-silicate glasses by magic angle spinning nuclear magnetic resonance (MAS-NMR). J Non-Cryst Solids. 2004;333:101-7.

13. Marquesi AR, Delbeni JRJ, Delben AST. Glass forming ability and thermal stability of oxyfluoride glasses. J Therm Anal Calorim. 2009;96(2):403-6.

14. Środa M. Effect of $\mathrm{LaF}_{3}$ admixture on thermal stability of borosilicate glasses. J Therm Anal Calorim. 2007;88(1):245-9.

15. Achary SN, Ambekar BR, Mathews MD, Tyagi AK, Moorthy PN. Thermochim Acta. 1998;320:239-43.

16. Görlich E. A quantitative theory of the character of chemical bonding in binary compounds. Nature. 1961;192:133-5. 